\title{
Life expectancy and health-adjusted life expectancy in people with inflammatory bowel disease
}

\author{
M. Ellen Kuenzig PhD, Douglas G. Manuel MD MSc, Jessy Donelle MSc, Eric I. Benchimol MD PhD
}

Cite as: CMAJ 2020 November 9;192:E1394-1402. doi: 10.1503/cmaj.190976

\begin{abstract}
BACKGROUND: Inflammatory bowel disease (IBD) may be life-threatening and often reduces quality of life. We determined trends in life expectancy and health-adjusted life expectancy in people with and without IBD.
\end{abstract}

METHODS: We conducted a retrospective cohort study of population-level health administrative, demographic and health survey data available from databases in Ontario. We matched people with a diagnosis of IBD to those without a diagnosis of IBD. We used period life tables that were generated using age- and sex-specific 5-year mortality rates to calculate life expectancy (for 1996, 2000, 2008 and 2011). We incorporated the Health Utility Index
(National Population Health Study; Canadian Community Health Survey) to estimate health-adjusted life expectancy (for 1996, 2000 and 2008).

RESULTS: Life expectancy in patients with IBD increased between 1996 and 2011 (females: from 75.5 to $78.4 \mathrm{yr}$, difference: $2.9 \mathrm{yr}$ [95\% confidence interval $(\mathrm{Cl}) 1.3$ to 4.5]; males: from 72.2 to $75.5 \mathrm{yr}$, difference: $3.2 \mathrm{yr}$ [95\% Cl 2.1 to 4.4]). Between 1996 and 2008, health-adjusted life expectancy decreased among males by 3.9 years ( $95 \% \mathrm{Cl} 1.2$ to 6.6$)$. There was no statistically significant change in healthadjusted life expectancy among females with IBD (difference: $2.0 \mathrm{yr}, 95 \% \mathrm{Cl}-1.6$ to 5.7). Life expectancy and health-adjusted life expectancy were lower in people with
IBD compared with those without IBD. Differences in life expectancy in people with and without IBD ranged from 6.6 to 8.1 years in females and 5.0 to 6.1 years in males, depending on the year. Differences in health-adjusted life expectancy for people with and without IBD ranged from 9.5 to 13.5 years in females and 2.6 to 6.7 years in males.

INTERPRETATION: Whilst life expectancy has increased among people with IBD, a gap in life expectancy between those with and without IBD remains, and the effect of pain on daily functioning contributes substantially to reduced health-adjusted life expectancy, suggesting that improved pain mitigation strategies should be implemented. nflammatory bowel disease (IBD), including subtypes Crohn disease and ulcerative colitis, is a chronic immune-mediated disease of the gastrointestinal tract with a relapsing and remitting course that results in stress ${ }^{1}$ and decreased quality of life. ${ }^{2}$ Management of IBD has improved through increased access to specialist care, ${ }^{3,4}$ biologic therapies and a treat-to-target approach (treatment aimed at minimizing inflammation and preventing disease progression). Specialist IBD care improves outcomes and reduces mortality. ${ }^{4,5}$ Biologics improve quality of life ${ }^{6,7}$ but may increase the risk of serious infection and malignant disease, particularly in older adults. ${ }^{8,9}$ Changes to IBD management and medication may have affected life expectancy and quality of life.

Relative to the general population, mortality is elevated in Crohn disease, ${ }^{10}$ studies evaluating mortality in ulcerative colitis have not been conclusive. ${ }^{11-14}$ Most studies evaluating mortality were conducted before the biologic era, and none evaluated life expectancy or health-adjusted life expectancy.

We sought to describe time trends in life expectancy and health-adjusted life expectancy in people with and without IBD in a population-based sample of residents of Ontario.

\section{Methods}

\section{Study design and data sources}

We conducted a matched cohort study comparing trends in life expectancy and health-adjusted life expectancy in people with and without IBD. We included all those with prevalent cases of IBD who were alive on July 1, 1996, 2000, 2008 and 2011. We matched all people with a diagnosis of IBD who were alive on July 1, 1996, 2000, 2008 and 2011, to 5 people without a diagnosis of IBD, based on age, sex, rural or urban residence and mean 
neighbourhood income quintile (a validated proxy for individual income ${ }^{25}$ ) at the time of survey or index date for those not participating in a survey. All patients had been diagnosed with IBD at least 6 months before responding to a Statistics Canada survey. We matched people with IBD who responded to a Statistics Canada survey to people without IBD who responded to the same survey and followed them for 5 years from the index date, or until death or migration from Ontario.

We used databases linked deterministically using a unique identifier from 3 sources: health administrative data, including all outpatient visits, visits to the emergency department and admissions to hospital, used to derive the Ontario Crohn's and Colitis Cohort of people with IBD in Ontario; Statistics Canada surveys, which include information on the Health Utility Index (HUI) used in health-adjusted life expectancy calculations; and population demographic and death registry data, including Vital Statistics and the Registered Persons Database (Appendix 1, Table S1, available at www.cmaj.ca/lookup/doi/10.1503/ cmaj.190976/tab-related-content). Data were available for all legal residents of Ontario with a health card (>99\% of the population). Statistics Canada surveys are available for a sample of Ontario residents and are weighted to ensure estimates are representative of the population of the province. Data were available to researchers at ICES in uncleaned format. ${ }^{15}$

We identified prevalent cases of IBD from the Ontario Crohn's and Colitis Cohort, derived from health administrative data using validated age-specific algorithms based on encounters in health services and using International Classification of Diseases, 9th Revision (ICD-9) codes 555 (Crohn disease) and 556 (ulcerative colitis), and International Statistical Classification of Diseases and Related Health Problems, 10th Revision (ICD-10) codes K50 (Crohn disease) and K51 (ulcerative colitis) (Appendix 1, Table S2). ${ }^{16,17}$

We classified survey respondents as having IBD if they were contained within the Ontario Crohn's and Colitis Cohort.

When abstracting data from Statistics Canada Surveys, we deterministically linked respondents to the 1996/97 National Population Health Survey (NPHS) and Canadian Community Health Survey (CCHS) 1.1 and 2009/10 cycles, who provided consent to do so, to their administrative data records. ${ }^{18-20}$ These surveys used a multistage stratified cluster design representing $90 \%$ of the Canadian population who were 12 years of age and older. ${ }^{21}$ In Ontario, Cycle 1.1 had a response rate of $82.0 \%$ and the $2009 / 10$ cycle had a response rate of $70.0 \% .^{19,22}$ Detailed descriptions of the methods used to assign survey weights are available in the survey documentation. ${ }^{18-20}$ These NPHS and CCHS cycles were selected because they included the Health Utility Index Mark-3, a utility-based measure of health-related quality of life describing how health interferes with daily tasks, including vision, hearing, speech, ambulation, dexterity, emotional well-being, cognitive functioning and pain. ${ }^{23,24}$ We used an overall estimate of health-related quality of life calculated from all 8 attributes and scores specific to pain and emotional well-being. A score of 1 is considered perfect health and a score of 0 is considered equivalent to being dead. The 2009/10 CCHS also includes self-reported IBD (for validation using the Ontario Crohn's and Colitis Cohort as the gold standard see Appendix 2, available at www.cmaj.ca/ lookup/doi/10.1503/cmaj.190976/tab-related-content). The characteristics of people with and without IBD who did and did not respond to each cycle of the CCHS are described in Appendix 1 , Table S3.

\section{Statistical analysis}

\section{Life expectancy at birth and mortality}

We calculated life expectancy at birth using period lifetables as described by Chiang. ${ }^{26}$ This approach calculates expected length of life assuming that age- and sex-specific mortality rates for a specific time period remain constant throughout a person's life. ${ }^{26}$ Life expectancy is interpreted as the expected length of life if a hypothetical cohort was subjected to the mortality experience of people with IBD, Crohn disease, ulcerative colitis and those without IBD for each included year (1996, 2000, 2008 and 2011). The hypothetical cohort represents people with IBD, Crohn disease and ulcerative colitis who were included in the Ontario Crohn's and Colitis Cohort at each of the 4 different time points but had no underlying characteristics before being subjected to the mortality risk of the open population of people with and without IBD. Diagnosis occurs at different ages; therefore, people will have varying lengths of disease duration. There were no transitions between states of diagnosis, treatment or resolution.

We used 5-year mortality rates in standard age groups $(<1$, 1-4, 5-9, through to $\geq 90 \mathrm{yr}$ ) with Hsieh's modification for the last age group. ${ }^{26,27}$ We estimated life expectancy separately for males and females, as well as for those with IBD, Crohn disease, ulcerative colitis and those without IBD. We used single-state life tables, meaning that all individuals contributing to a life table were prevalent cases of IBD (or matched individuals without IBD for the non-IBD life tables). We calculated life expectancy as of July 1 of each included year.

We used modified Poisson regression for binary outcomes to compare mortality in people with and without IBD; ${ }^{28}$ stratified by sex but with no additional adjustment. We conducted separate analyses for males and females, and for IBD, Crohn disease, ulcerative colitis and those people without IBD.

\section{Health-adjusted life expectancy}

We calculated the mean HUI for males and females with and without IBD for all ages combined and each age- and sex-specific group. We calculated standard errors with Taylor linearization to incorporate survey weights. ${ }^{29}$ Ten-year age intervals were used to ensure a sufficient sample size. Because the Statistics Canada surveys did not include anyone less than 12 years of age, a HUI of 1 was assigned to the youngest age intervals.

Health-adjusted life expectancy at birth represents the number of years that a person is expected to live in full health. We calculated this using Sullivan's approach, which weights the years of life lived in each age interval by the mean HUI for that specific age interval. ${ }^{30}$ For example, if there were 3000 person-years lived in a given age interval and the mean $\mathrm{HUI}$ among survey respondents in this age group was 0.9 , these 3000 person-years would be equivalent to 2700 high-quality person-years. We assumed 
that the mean HUI for each age and sex stratum were representative of the entire population with IBD for that stratum; we used these values to weight years lived in that stratum.

We calculated health-adjusted life expectancy by incorporating HUI calculated from all attributes and then incorporating single-attribute HUI specific to emotional well-being and pain. ${ }^{24}$ We also calculated the ratio of health-adjusted life expectancy to life expectancy, which estimates the proportion of expected years of life lived in full health. We selected emotional well-being and pain because these are the domains most likely to be affected by IBD. Pain is a common symptom of IBD that can persist even during disease remission; ${ }^{31-33}$ depression and anxiety occur more often in patients with IBD than in the general population. ${ }^{34,35}$

We considered differences in life expectancy and healthadjusted life expectancy to be significant when the 95\% confidence intervals ( $\mathrm{Cls}$ ) around the differences between groups did not cross zero. Statistical analyses were conducted using SAS 9.4 (SAS Institute Inc.).

\section{Ethics approval}

This study was approved by the Research Ethics Board at the Children's Hospital of Eastern Ontario, Ottawa, Ontario.

\section{Results}

On July 1, 1996, 32818 people were living with IBD (matched to 163284 people without IBD), increasing to 83672 on July 1, 2011 (matched to 418360 people without IBD) (Table 1). The mean age of patients with prevalent IBD increased from 42.4 to 48.3 years. The proportion of female cases remained stable, ranging from $52 \%$ to $53 \%$. We removed 1 outlier with IBD who contributed substantially to the variability of estimated life expectancy (privacy regulations prevent a detailed description).

\section{Life expectancy}

We found that life expectancy at birth among females with IBD increased by 2.9 years ( $95 \% \mathrm{Cl} 1.3$ to 4.5 ) between 1996 (75.5 yr, $95 \% \mathrm{Cl} 74.0$ to 77.0 ) and 2011 (78.4 yr, 95\% Cl 77.7 to 79.1 ) (Table 2). Females with IBD had a consistently shorter life expectancy than females without IBD. Life expectancy increased significantly among females with Crohn disease (Appendix 1, Table S4) but not among those with ulcerative colitis (Appendix 1, Table S5). Mortality was significantly higher among females with IBD than females without IBD (Figure 1; Appendix 1, Table S6).

Table 1: Demographic characteristics of people with prevalent inflammatory bowel disease and matched people without inflammatory bowel disease, by year

\begin{tabular}{|c|c|c|c|c|c|c|c|c|}
\hline \multirow[b]{3}{*}{ Characteristic } & \multicolumn{2}{|c|}{1996} & \multicolumn{2}{|c|}{2000} & \multicolumn{2}{|c|}{2008} & \multicolumn{2}{|c|}{2011} \\
\hline & \multicolumn{8}{|c|}{ No. (\%) of participants* } \\
\hline & $\begin{array}{l}\text { With IBD } \\
n=32818\end{array}$ & $\begin{array}{c}\text { Without IBD } \\
n=163284\end{array}$ & $\begin{array}{l}\text { With IBD } \\
n=44601\end{array}$ & $\begin{array}{c}\text { Without IBD } \\
n=222126\end{array}$ & $\begin{array}{l}\text { With IBD } \\
n=69559\end{array}$ & $\begin{array}{c}\text { Without IBD } \\
n=347001\end{array}$ & $\begin{array}{l}\text { With IBD } \\
n=80276\end{array}$ & $\begin{array}{c}\text { Without IBD } \\
n=401036\end{array}$ \\
\hline $\begin{array}{l}\text { Age on July } 1 \text {, yr; mean } \pm \\
\text { SD }\end{array}$ & $42.40 \pm 16.59$ & $42.28 \pm 16.51$ & $44.21 \pm 16.66$ & $44.11 \pm 16.59$ & $47.34 \pm 16.86$ & $47.27 \pm 16.84$ & $48.30 \pm 16.95$ & $48.27 \pm 16.94$ \\
\hline $\begin{array}{l}\text { Age on July } 1, y r \text {; median } \\
\left(Q_{\text {med }} 1-Q_{\text {med }} 3\right)\end{array}$ & $40(30-53)$ & $40(30-53)$ & $42(32-55)$ & $42(32-55)$ & $46(35-59)$ & $46(35-58)$ & $48(36-60)$ & $48(36-60)$ \\
\hline Female sex & $17341(52.8)$ & $86142(52.8)$ & $23551(52.8)$ & $117187(52.8)$ & $36508(52.5)$ & $181982(52.4)$ & $41964(52.3)$ & $209606(52.3)$ \\
\hline Rural residence $\dagger$ & $4442(13.5)$ & $21415(13.1)$ & $5775(12.9)$ & $28013(12.6)$ & $8536(12.3)$ & $41905(12.1)$ & $9661(12.0)$ & $47961(12.0)$ \\
\hline \multicolumn{9}{|c|}{ Mean neighbourhood income quintile† } \\
\hline Q1 (lowest) & $5426(16.5)$ & $26946(16.5)$ & $7211(16.2)$ & $35857(16.1)$ & $11082(15.9)$ & $55250(15.9)$ & $12194(15.2)$ & $60905(15.2)$ \\
\hline Q2 & $6217(18.9)$ & $30886(18.9)$ & 8755 (19.6) & 43549 (19.6) & $12850(18.5)$ & $64021(18.4)$ & $14944(18.6)$ & $74638(18.6)$ \\
\hline Q3 & $6811(20.8)$ & 33898 (20.8) & $9216(20.7)$ & $45910(20.7)$ & $14109(20.3)$ & $70429(20.3)$ & $16302(20.3)$ & $81444(20.3)$ \\
\hline Q4 & 7102 (21.6) & $35343(21.6)$ & 9333 (20.9) & $46544(21.0)$ & $15551(22.4)$ & $77564(22.4)$ & $18285(22.8)$ & $91361(22.8)$ \\
\hline Q5 (highest) & $7262(22.1)$ & $36211(22.2)$ & $10086(22.6)$ & $50266(22.6)$ & $15967(23.0)$ & $79737(23.0)$ & $18551(23.1)$ & $92688(23.1)$ \\
\hline $\begin{array}{l}\text { Responded to NPHS/ } \\
\text { CCHS }\end{array}$ & $88(0.3)$ & $434(0.3)$ & $158(0.4)$ & $790(0.4)$ & $238(0.3)$ & $1176(0.3)$ & NA & NA \\
\hline \multicolumn{9}{|l|}{ Type of IBD } \\
\hline Crohn disease & $16804(51.2)$ & NA & 22253 (49.9) & NA & $33411(48.0)$ & NA & $37936(47.3)$ & NA \\
\hline Ulcerative colitis & $15158(46.2)$ & NA & $21042(47.2)$ & NA & $33717(48.5)$ & NA & $39028(48.6)$ & NA \\
\hline IBD unclassified & $856(2.6)$ & NA & $1306(2.9)$ & NA & $2431(3.5)$ & NA & $3312(4.1)$ & NA \\
\hline
\end{tabular}


We found that life expectancy at birth among males with IBD increased by 3.2 years (95\% Cl 2.1 to 4.4) between 1996 (72.2 yr, $95 \% \mathrm{Cl} 71.3$ to 73.1$)$ and 2011 (75.5 yr, 95\% Cl 74.8 to 76.2 ) (Table 2), and was shorter among males with IBD than males without IBD. Findings were similar for those with Crohn disease (Appendix 1, Table S4) and ulcerative colitis (Appendix 1, Table S5). Males with IBD had higher mortality than those without IBD (Figure 1; Appendix 1, Table S6).

\section{Health-adjusted life expectancy}

\section{Overall well-being}

The mean HUls for people with and without IBD are provided in Appendix 1, Table S7. We determined that health-adjusted life expectancy decreased among males with IBD by 3.9 years $(95 \%$ $\mathrm{Cl} 1.2$ to 6.6) between 1996 (67.0 yr, 95\% Cl 65.1 to 68.8) and 2008
(63.1 yr, 95\% Cl 61.0 to 65.1) and was stable in females with IBD (difference: $2.0 \mathrm{yr}, 95 \% \mathrm{Cl}-1.6$ to 5.7 ; 1996: $62.3 \mathrm{yr}, 95 \% \mathrm{Cl} 59.4$ to 65.2; 2008: $64.3 \mathrm{yr}, 95 \% \mathrm{Cl} 62.1$ to 66.6$)$, and among males and females without IBD (Table 2). Health-adjusted life expectancy was significantly reduced among patients with IBD (Table 2 ). We found similar results when we compared males and females with Crohn disease to people without IBD (Appendix 1, Table S4), whereas differences between people with and without ulcerative colitis varied over time (Appendix 1, Table S5).

For females, we determined that the ratio of health-adjusted life expectancy to life expectancy ranged from 0.77 to 0.83 among people with IBD and from 0.86 to 0.91 among those without IBD (Table 2; Figure 2A and B).

This ratio was similar for Crohn disease (Appendix 1 , Table S4; Figure S1A and B) and ulcerative colitis (Appendix 1, Table S5; Figure S2A and $B$ ). In males, this ratio ranged from

Table 2 (part 1 of 2): Comparison of life expectancy and health-adjusted life expectancy among females and males with inflammatory bowel disease and matched people without inflammatory bowel disease, by year

1996

\section{Participants with IBD}

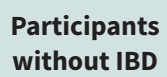

2000

$\begin{array}{cl}\text { Participants } & \text { Participants } \\ \text { with IBD } & \text { without IBD }\end{array}$

Variable

Life expectancy, yr $(95 \% \mathrm{CI})$

\begin{tabular}{|lllllll}
\hline Female & $75.5(74.0$ to 77.0$)$ & $82.1(81.7$ to 82.5$)$ & $-6.6(-8.1$ to -5.1$)$ ฯ & $76.5(75.8$ to 77.3$)$ & $83.6(83.2$ to 83.9$)$ & $-7.0(-7.9$ to -6.2$)$ ฯ \\
\hline Male & $72.2(71.3$ to 73.1$)$ & $77.6(77.1$ to 78.0$)$ & $-5.4(-6.4$ to -4.3$)$ ฯ & $74.4(73.7$ to 75.2$)$ & $79.4(79.0$ to 79.8$)$ & $-5.0(-5.8$ to -4.2$)$ ฯ
\end{tabular}

Health-adjusted life expectancy, yr $(95 \% \mathrm{Cl})$

Overall

\begin{tabular}{|c|c|c|c|c|c|c|}
\hline Female & 62.3 (59.4 to 65.2 ) & 74.3 (73.1 to 75.6$)$ & $-12.0(-15.1$ to -8.9$)$ ฯ & 59.2 (56.8 to 61.7 ) & 72.7 (71.6 to 73.9$)$ & $-13.5(-16.2$ to -10.8$)$ ฯ \\
\hline Difference $\ddagger$ & 13.2 & 7.8 & & 17.3 & 10.8 & \\
\hline Ratio§ & 0.83 & 0.91 & & 0.77 & 0.87 & \\
\hline Male & 67.0 (65.1 to 68.8$)$ & 69.6 (68.2 to 71.0$)$ & $-2.6(-4.9$ to -0.4$)$ ฯ & 65.4 (62.9 to 68.0$)$ & 71.9 (70.9 to 72.9 ) & $-6.5(-9.2$ to -3.7$)$ ฯ \\
\hline Difference $\ddagger$ & 5.3 & 8.0 & & 9.0 & 7.5 & \\
\hline Ratio§ & 0.93 & 0.90 & & 0.88 & 0.91 & \\
\hline \multicolumn{7}{|l|}{ Pain-specific } \\
\hline Female & 65.7 (61.9 to 69.6$)$ & 77.2 (75.8 to 78.5 ) & $-11.5(-15.5$ to -7.4$)$ ฯ & 62.2 (59.1 to 65.2 ) & 76.3 (75.0 to 77.6$)$ & $-14.2(-17.4$ to -10.9$)$ ฯ \\
\hline Difference & 9.8 & 4.9 & & 14.4 & 7.2 & \\
\hline Ratio§ & 0.87 & 0.94 & & 0.81 & 0.91 & \\
\hline Male & 68.1 (65.9 to 70.3$)$ & 74.4 (73.3 to 75.4$)$ & $-6.2(-8.7$ to -3.8$)$ ฯ & 66.7 (63.8 to 69.6$)$ & 75.6 (74.4 to 76.8 ) & $-8.9(-12.1$ to -5.7$)$ ฯ \\
\hline Difference $\ddagger$ & 4.1 & 3.2 & & 7.8 & 3.8 & \\
\hline Ratio§ & 0.94 & 0.96 & & 0.90 & 0.95 & \\
\hline \multicolumn{7}{|c|}{ Emotional well-being } \\
\hline Female & 74.7 (73.1 to 76.2$)$ & $80.8(80.2$ to 81.5$)$ & $-6.2(-7.8$ to -4.5$)$ ฯ & 74.1 (73.0 to 75.2 ) & 80.8 ( 80.1 to 81.5 ) & $-6.7(-8.0$ to -5.5$)$ ฯ \\
\hline Differenceł & 0.8 & 1.3 & & 2.4 & 2.7 & \\
\hline Ratio§ & 0.99 & 0.98 & & 0.97 & 0.97 & \\
\hline Male & 71.4 (70.4 to 72.5$)$ & 75.8 (74.8 to 76.8$)$ & $-4.3(-5.8$ to -2.9$)$ ฯ & $72.0(70.4$ to 73.5$)$ & 77.3 (76.7 to 77.9$)$ & $-4.3(-7.0$ to -3.7$)$ ฯ \\
\hline Difference $\ddagger$ & 0.8 & 1.8 & & 2.5 & 2.1 & \\
\hline Ratio§ & 0.99 & 0.98 & & 0.97 & 0.97 & \\
\hline
\end{tabular}


Table 2: (part 2 of 2): Comparison of life expectancy and health-adjusted life expectancy among females and males with inflammatory bowel disease and matched people without inflammatory bowel disease, by year

\section{8}

\section{Participants Participants}

Variable

Life expectancy, yr (95\% Cl)

Female

78.0

(77.3 to 78.7$)$

75.1

(74.5 to 75.7 )
2011*

Participants Participants with IBD without IBD Difference
Difference over time $†$

Participants Participants with IBD without IBD

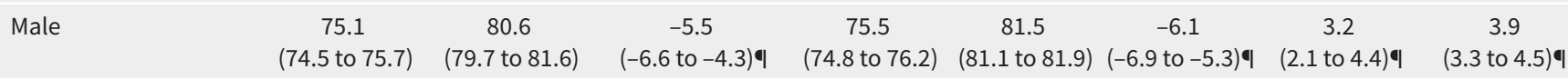

Health-adjusted life expectancy, yr $(95 \% \mathrm{Cl})$

Overall

\begin{tabular}{|c|c|c|c|c|c|c|c|c|}
\hline Female & $\begin{array}{c}64.3 \\
\text { (62.1 to } 66.6)\end{array}$ & $\begin{array}{c}73.9 \\
\text { (72.5 to } 75.3 \text { ) }\end{array}$ & $\begin{array}{c}-9.5 \\
(-12.2 \text { to }-6.9) \text { ฯ }\end{array}$ & - & - & - & $\begin{array}{c}2.0 \\
(-1.6 \text { to } 5.7)\end{array}$ & $\begin{array}{c}-0.4 \\
(-2.3 \text { to } 1.5)\end{array}$ \\
\hline Difference $\ddagger$ & 13.6 & 12.2 & & - & - & - & & \\
\hline Ratio§ & 0.83 & 0.86 & & - & - & - & & \\
\hline Male & $\begin{array}{c}63.1 \\
(61.0 \text { to } 65.1)\end{array}$ & $\begin{array}{c}69.8 \\
\text { (68.4 to } 71.2)\end{array}$ & $\begin{array}{c}-6.7 \\
(-9.2 \text { to }-4.3) \text { ฯ }\end{array}$ & - & - & - & $\begin{array}{c}-3.9 \\
(-6.6 \text { to }-1.2)\end{array}$ & $\begin{array}{c}0.2 \\
(-1.7 \text { to } 2.2)\end{array}$ \\
\hline Difference $\ddagger$ & 12.1 & 10.8 & & - & - & - & & \\
\hline Ratio§ & 0.84 & 0.87 & & - & - & - & & \\
\hline \multicolumn{9}{|l|}{ Pain-specific } \\
\hline Female & $\begin{array}{c}66.1 \\
\text { (63.6 to 68.7) }\end{array}$ & $\begin{array}{c}79.4 \\
\text { (78.4 to } 80.3 \text { ) }\end{array}$ & $\begin{array}{c}-13.2 \\
(-16.0 \text { to }-10.5)\end{array}$ & - & - & - & $\begin{array}{c}0.4 \\
(-4.2 \text { to } 5.0)\end{array}$ & $\begin{array}{c}2.2 \\
\text { (0.5 to } 4.9)\end{array}$ \\
\hline Difference $\ddagger$ & 11.9 & 6.7 & & - & - & & & \\
\hline Ratio§ & 0.85 & 0.92 & & - & - & & & \\
\hline Male & $\begin{array}{c}65.5 \\
\text { (63.1 to } 67.9)\end{array}$ & $\begin{array}{c}75.2 \\
\text { (73.7 to } 76.8)\end{array}$ & $\begin{array}{c}-9.7 \\
(-12.6 \text { to }-6.8) \text { ฯ }\end{array}$ & - & - & - & $\begin{array}{c}-2.6 \\
(-5.9 \text { to } 0.6)\end{array}$ & $\begin{array}{c}0.9 \\
(-1.0 \text { to } 2.7)\end{array}$ \\
\hline Difference $\ddagger$ & 9.6 & 5.4 & & - & - & & & \\
\hline Ratio§ & 0.87 & 0.93 & & - & - & & & \\
\hline \multicolumn{9}{|c|}{ Emotional well-being } \\
\hline Female & $\begin{array}{c}76.2 \\
\text { (75.2 to } 77.1)\end{array}$ & $\begin{array}{c}83.8 \\
\text { (83.4 to } 84.3 \text { ) }\end{array}$ & $\begin{array}{c}-7.7 \\
(-8.7 \text { to }-6.6) \text { ฯ }\end{array}$ & - & - & - & $\begin{array}{c}1.5 \\
(-0.3 \text { to } 3.3)\end{array}$ & $\begin{array}{c}3.0 \\
(2.2 \text { to } 3.8)\end{array}$ \\
\hline Difference & 1.8 & 2.2 & & - & - & & & \\
\hline Ratio§ & 0.98 & 0.97 & & - & - & & & \\
\hline Male & $\begin{array}{c}72.5 \\
\text { (71.5 to } 73.6)\end{array}$ & $\begin{array}{c}77.9 \\
\text { (76.7 to } 79.0 \text { ) }\end{array}$ & $\begin{array}{c}-5.3 \\
(-6.9 \text { to }-3.8) \text { ฯ }\end{array}$ & - & - & - & $\begin{array}{c}1.1 \\
(-0.4 \text { to } 2.6)\end{array}$ & $\begin{array}{c}2.1 \\
\text { (0.6 to } 3.6) \text { व }\end{array}$ \\
\hline Difference $\ddagger$ & 2.6 & 2.7 & & - & - & & & \\
\hline Ratio§ & 0.97 & 0.97 & & - & - & & & \\
\hline
\end{tabular}

Note: $\mathrm{Cl}=$ confidence interval, $\mathrm{IBD}=$ inflammatory bowel disease.

*We could not calculate health-adjusted life expectancy in 2011 because there was no corresponding Statistics Canada population health survey that included the Health Utility Index Mark-3.

†Difference between 2011 and 1996 for life expectancy and difference between 2008 and 1996 for health-adjusted life expectancy.

$\ddagger$ Difference between life expectancy and health-adjusted life expectancy.

$\S$ Ratio of health-adjusted life expectancy to life expectancy.

ISignificant difference.

0.84 to 0.93 among those with IBD and from 0.87 to 0.90 among those without IBD (Appendix 1, Table S4; Figure 2C and $D)$. Our findings were similar among males with Crohn disease (Appendix 1, Table S3; Figure S1C and D) and among those with ulcerative colitis (Appendix 1, Table S5; Figure S2C and D).

\section{Emotional well-being}

The mean single-attribute utilities reflecting the effect of emotional well-being on health status ${ }^{24}$ is provided in Appendix 1, Table S7. We found that health-adjusted life expectancy did not change over time in people with IBD (difference among females: $1.5 \mathrm{yr}, 95 \% \mathrm{Cl}-0.3$ to 3.3; difference among males: $1.1 \mathrm{yr}, 95 \% \mathrm{Cl}$ 


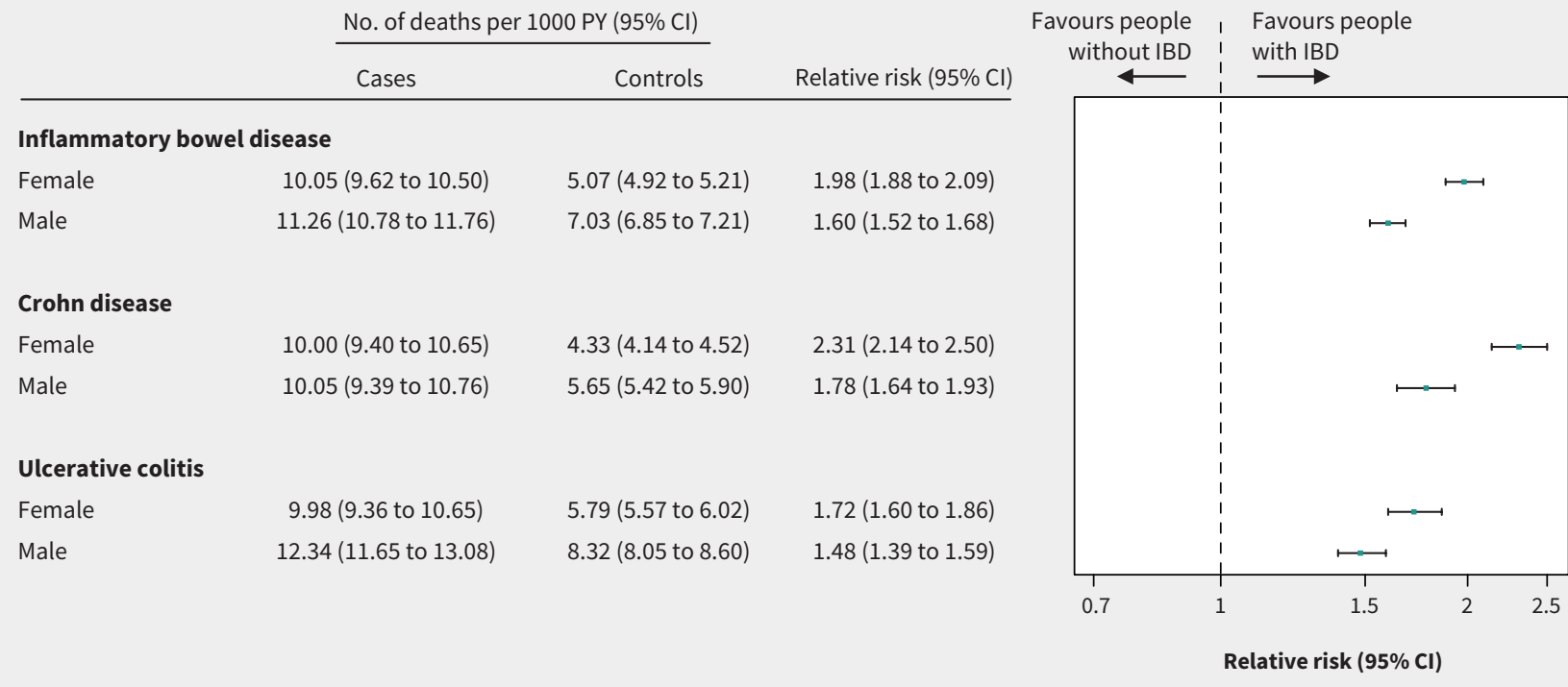

Figure 1: Comparison of mortality among people with and without inflammatory bowel disease (IBD), presented as mortality rates per 1000 personyears (PY) in both groups and relative risks with 95\% confidence intervals $(\mathrm{CI})$.

-0.4 to 2.6 ) and increased in people without IBD (difference among females: $3.0 \mathrm{yr}, 95 \% \mathrm{Cl} 2.2$ to 3.8 ; difference among males: $2.1 \mathrm{yr}, 95 \% \mathrm{Cl} 0.6$ to 3.6). Health-adjusted life expectancy was reduced among people with IBD at all time points (Figure 2; Table 2). The ratio of health-adjusted life expectancy to life expectancy ranged from 0.97 to 0.99 for people with IBD and from 0.97 to 0.98 for people without IBD (Figure 2; Table 2). We also determined that health-adjusted life expectancy attributed to emotional well-being remained constant over time among people with IBD and increased among those without IBD. This was true for both people with Crohn disease (Appendix 1, Table S4 and Figure S1) and those with ulcerative colitis (Appendix 1, Table S5 and Figure S2).

\section{Pain}

Table S7 in Appendix 1 provides the mean single-attribute utilities reflecting the effect of pain on health status for people with and without IBD. ${ }^{24}$ We found that the health-adjusted life expectancy among females with IBD was 65.7 years $(95 \% \mathrm{Cl} 61.9$ to $69.6)$ in 1996 and 66.1 years ( $95 \% \mathrm{Cl} 63.6$ to 68.7 ) in 2008, and was constant over time (difference: $0.4 \mathrm{yr}, 95 \% \mathrm{Cl}-4.2$ to 5.0; Figure 2A; Table 2); health-adjusted life expectancy increased from 77.2 years ( $95 \% 75.8$ to 78.5 ) to 79.4 years $(95 \% \mathrm{Cl} 78.4$ to 80.3 ) among females without IBD (difference: $2.2 \mathrm{yr}, 95 \% \mathrm{Cl} 0.5$ to 4.9 ; Figure 2B; Table 2). Findings were similar among people with Crohn disease (Appendix 1, Figure S1 and Table S4), whereas pain-attributed health-adjusted life expectancy was stable among females with and without ulcerative colitis (Appendix 1, Figures S1 and S2 and Table S5). The ratio of health-adjusted life expectancy to life expectancy ranged from 0.81 to 0.87 for females with IBD and from 0.91 to 0.94 for females without IBD (Figure 2; Table 2), with similar ratios for those with Crohn disease (Appendix 1, Figure S1 and Table S4) and slightly higher ratios among females with ulcerative colitis (Appendix 1, Figure S2 and Table S5).

We found that health-adjusted life expectancy calculated using the pain-attributed utility ${ }^{24}$ was stable among males with IBD (1996: $68.1 \mathrm{yr}, 95 \% \mathrm{Cl} 65.9$ to 70.3 ; 2008: $65.6 \mathrm{yr}, 95 \% \mathrm{Cl} 63.1$ to 67.9 ; difference: $-2.6 \mathrm{yr}, 95 \% \mathrm{Cl}-5.9$ to $0.6 \mathrm{yr}$; Figure $2 \mathrm{C}$; Table 2), decreased over time among people with Crohn disease (1996: $67.2 \mathrm{yr}, 95 \% \mathrm{Cl} 65.0$ to 69.4 ; 2008: $60.0 \mathrm{yr}, 95 \% \mathrm{Cl} 56.7$ to 63.3; difference: $-7.2 \mathrm{yr}, 95 \% \mathrm{Cl}-11.2$ to -3.3 ; Appendix 1, Figure S1C and Table S4) and increased over time among people with ulcerative colitis (1996: $68.2 \mathrm{yr}, 95 \% \mathrm{Cl} 64.7$ to 71.6 ; 2008: $72.7 \mathrm{yr}, 95 \% \mathrm{Cl} 70.4$ to 75.1 ; difference: $4.5 \mathrm{yr}, 95 \% \mathrm{Cl} 0.4$ to 8.7 ; Appendix 1, Figure S2C and Table S5). The ratio of healthadjusted life expectancy to life expectancy ranged from 0.87 to 0.94 in males with IBD and from 0.93 to 0.96 in males without IBD (Figures 2C, 2D; Table 2); these ratios were similar in both males with Crohn disease (Appendix 1, Figures S1C, S1D and Table S4) and those with ulcerative colitis (Appendix 1, Figures S2C, S2D and Table S5).

\section{Interpretation}

Although life expectancy between 1996 and 2011 has increased among people with IBD, it remains reduced compared with people without IBD. Furthermore, increases in life expectancy have not been mirrored by increased health-adjusted life expectancy, which has either remained stable (females) or declined (males). We found that the gap in health-adjusted life expectancy between those with and without IBD was large when evaluating both general well-being and the effect of pain. These trends were observed over a time period that saw the introduction of 2 biologics for IBD treatment in Canada: infliximab (2001) and adalimumab (2004). Our findings of higher mortality risk are consistent 

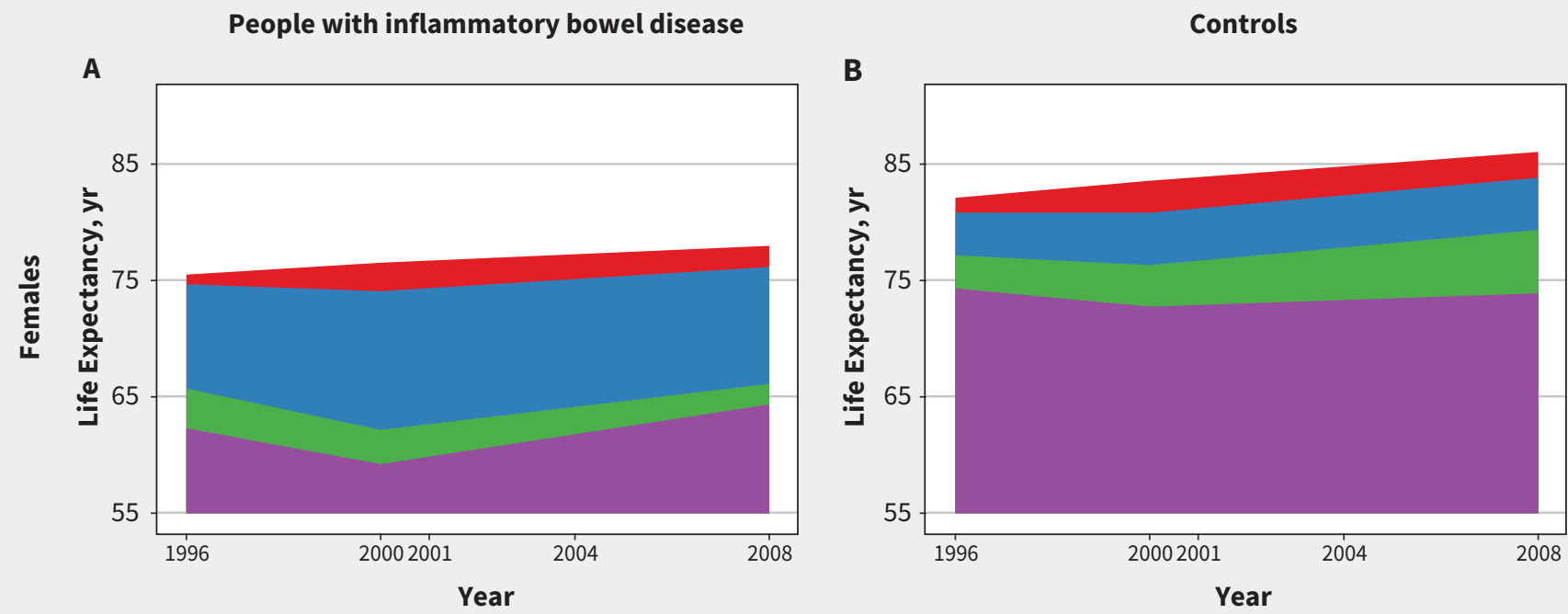

C

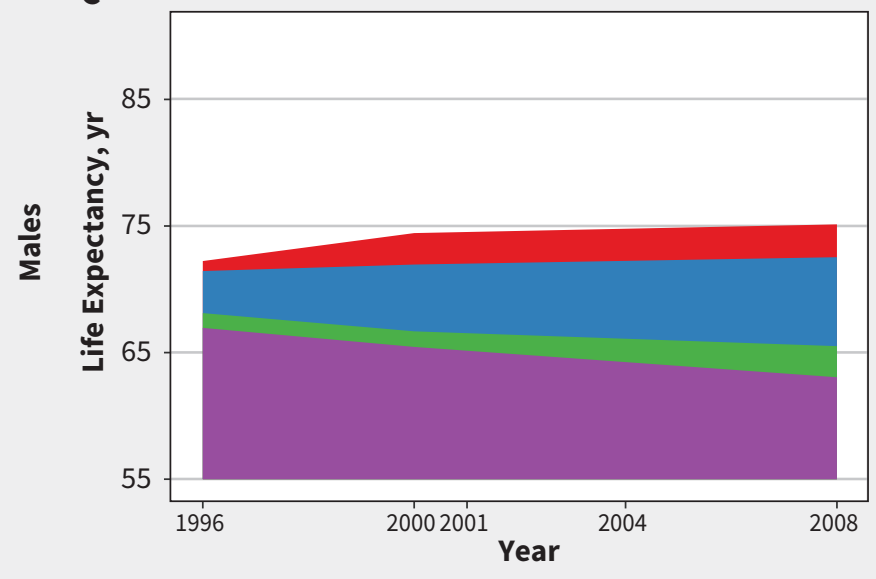

D

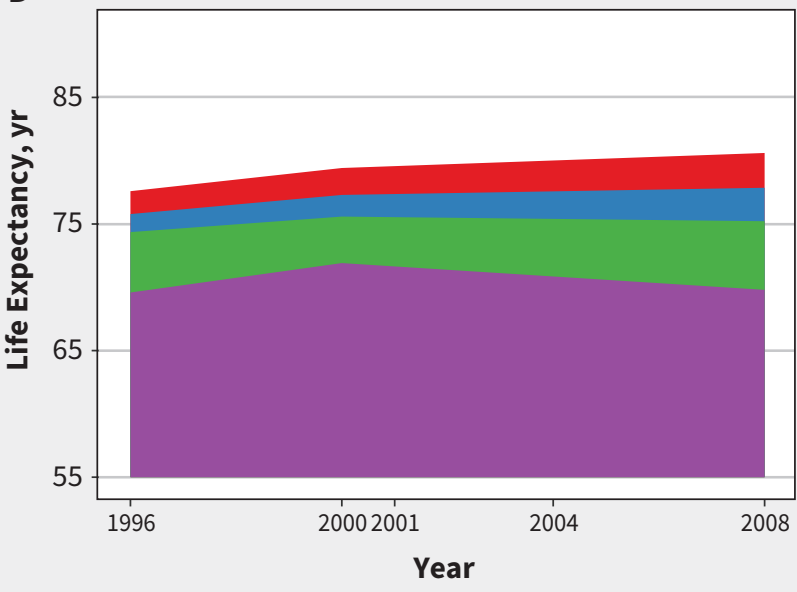

Life expectancy

Emotion-adjusted life expectancy

Pain-adjusted life expectancy

Health-adjusted life expectancy

Figure 2: Life expectancy and health-adjusted life expectancy at birth, broken down by contribution of each component of life expectancy, in (A) females and (B) males with inflammatory bowel disease and matched (C) females and (D) males without inflammatory bowel disease (IBD) over a time period in which infliximab (2001) and adalimumab (2004) were introduced.

with previous research; we additionally quantified the life expectancy and health-adjusted life expectancy in people with IBD and included the effect of emotional well-being and pain in estimates of health-adjusted life expectancy.

Data on trends of both life expectancy and health-related quality of life among people with IBD are sparse. Notable improvements in health-related quality of life have been reported in patients with IBD who receive biologics. ${ }^{6,7}$ However, we found decreasing health-adjusted life expectancy, particularly in males, in the biologic era. Anxiety and depression are more common in people with IBD relative to the general population; ${ }^{34,35}$ however, the effect of emotional well-being on healthadjusted life expectancy appeared to be limited. In contrast, people with IBD reported a high degree of impairment due to pain, and the differences between people with and without IBD was greater for females than males. Females with IBD report a higher symptom burden ${ }^{36}$ and are more likely to have pain-related comorbidities such as arthropathies. ${ }^{37,38}$ About $20 \%-40 \%$ of patients with IBD have co-occurring irritable bowel syndrome; ${ }^{39,40}$ abdominal pain persists when patients are in remission and is often unaddressed by health care providers. ${ }^{31,33}$ In light of the prevalence of pain in patients with IBD and its effect on healthrelated quality of life, improved pain-management strategies should be developed.

\section{Limitations}

Our results may have been confounded by disease phenotype or severity (not available in health administrative data). People with 
active or severe IBD likely have a decreased HUI compared with those whose disease is quiescent, and these people may have been less able to respond to lengthy Statistics Canada surveys. Consequently, our study may have underestimated the effect of IBD on health-adjusted life expectancy. Further, populationbased data on medication use for individuals who were younger than 65 years of age were not available, and data on potential environmental or other confounders (e.g., smoking and ethnicity) were only available for the small proportion of patients responding to a Statistics Canada survey. Therefore, we were not able to specifically evaluate how these confounders may affect life expectancy and health-adjusted life expectancy. In addition, life expectancy among people living with IBD may vary depending on age at IBD diagnosis, a difference that we may have missed by not comparing the life expectancies of individuals with a diagnosis of IBD at various ages. Further, mortality may increase with disease duration, which would violate the assumption that age- and sex-specific mortality rates remain constant over a person's lifetime that is required when using lifetables. ${ }^{26}$ Because we included prevalent rather than incident cases of IBD, we did not have data on the age of diagnosis or disease duration for people with IBD in our study. Our study may also have been at risk of immortal time bias if patients with IBD died before meeting the full case definition required by the validated algorithms. ${ }^{16,17}$ However, it is much more likely that a patient with IBD will die after long-term complications of IBD or its therapy rather than within the first few months of having the disease. Thus, we do not expect immortal time bias to affect our findings.

Period life expectancy is challenging to interpret because the measure represents the mortality of a hypothetical cohort with no real cohort comparison. ${ }^{41}$ Instead, period life expectancy is a descriptive measure of mortality that translates cross-sectional mortality into a more intuitive longitudinal or life course perspective. ${ }^{42} \mathrm{~A}$ period life expectancy should not be interpreted as representing people who are born with IBD or how long a person with IBD would actually live. A realistic estimate of length of life is estimated using cohort life expectancy by observing survival over time, or by projecting or extending a cohort survival into the future.

Our use of a general measure of health-related quality of life may have introduced bias. The HUI was not designed to reflect the specific effect of IBD on health-related quality of life. Although disease characteristics may play a role in the increased effect of pain among females with IBD (i.e., females typically have more severe disease postadolescence), other conditions not measured in our study that occur more frequently in females with IBD may have also contributed to the observed difference in pain-related health-adjusted life expectancy.

As with all studies using health administrative data, our findings are subject to a risk of misclassification bias. ${ }^{43}$ However, we used validated algorithms to identify people with IBD and to classify them as having Crohn disease and ulcerative colitis, ${ }^{16,17}$ and self-reported IBD was concordant with our administrative data case definition.

People with IBD often have systemic inflammation, in addition to inflammation of the gastrointestinal tract. As a result, they are at increased risk of a cardiovascular event, malignant disease, arthritis, osteoporosis and mental illness. In addition, the medications used to treat IBD may result in an increased risk of infection or malignant disease..$^{8,9,44,45}$ Future research is needed to determine the contribution of comorbid conditions and medication use in explaining the gap in life expectancy among people with and without IBD.

\section{Conclusion}

Whilst life expectancy has increased among people with IBD, a gap in life expectancy between those with and without IBD remains, and the effect of pain on daily functioning contributes substantially to reduced health-adjusted life expectancy.

\section{References}

1. Targownik LE, Sexton KA, Bernstein MT, et al. The relationship among perceived stress, symptoms, and inflammation in persons with inflammatory bowel disease. Am J Gastroenterol. Am J Gastroenterol 2015;110:1001-12.

2. Lönnfors S, Vermeire S, Greco M, et al. IBD and health-related quality of life Discovering the true impact. J Crohns Colitis 2014;8:1281-6.

3. Benchimol El, Guttmann A, To T, et al. Changes to surgical and hospitalization rates of pediatric inflammatory bowel disease in Ontario, Canada (1994-2007). Inflamm Bowel Dis 2011;17:2153-61.

4. Nguyen GC, Nugent Z, Shaw S, et al. Outcomes of patients with Crohn's disease improved from 1988 to 2008 and were associated with increased specialist care. Gastroenterology 2011;141:90-7.

5. Murthy SK, Steinhart AH, Tinmouth J, et al. Impact of gastroenterologist care on health outcomes of hospitalised ulcerative colitis patients. Gut 2012;61: 1410-6.

6. Vogelaar L, Spijker AV, van der Woude J. The impact of biologics on healthrelated quality of life in patients with inflammatory bowel disease. Clin Exp Gastroenterol 2009;2:101-9.

7. LeBlanc K, Mosli MH, Parker CE, et al. The impact of biological interventions for ulcerative colitis on health-related quality of life. Cochrane Database Syst Rev 2015;(9):CD008655.

8. Cottone M, Kohn A, Daperno M, et al. Advanced age is an independent risk factor for severe infections and mortality in patients given anti-tumor necrosis factor therapy for inflammatory bowel disease. Clin Gastroenterol Hepatol 2011;9:30-5.

9. Lobatón T, Ferrante M, Rutgeerts P, et al. Efficacy and safety of anti-TNF therapy in elderly patients with inflammatory bowel disease. Aliment Pharmacol Ther 2015;42:441-51.

10. Canavan C, Abrams KR, Mayberry JF. Meta-analysis: mortality in Crohn's disease. Aliment Pharmacol Ther 2007;25:861-70.

11. Jess T, Gamborg M, Munkholm P, et al. Overall and cause-specific mortality in ulcerative colitis: meta-analysis of population-based inception cohort studies. Am J Gastroenterol 2007;102:609-17.

12. Duuricová D, Pedersen N, Elkjaer M, et al. Overall and cause-specific mortality in Crohn's disease: a meta-analysis of population-based studies. Inflamm Bowel Dis 2010;16:347-53.

13. Jess T, Frisch M, Simonsen J. Trends in overall and cause-specific mortality among patients with inflammatory bowel disease from 1982 to 2010. Clin Gastroenterol Hepatol 2013;11:43-8.

14. Olén O, Askling J, Sachs MC, et al. Increased mortality of patients with childhoodonset inflammatory bowel diseases, compared with the general population. Gastroenterology 2019;156:614-22.

15. ICES Data Dictionary. ICES; 2018. Available: https://datadictionary.ices.on.ca (accessed 2018 Aug. 28).

16. Benchimol El, Guttmann A, Griffiths AM, et al. Increasing incidence of paediatric inflammatory bowel disease in Ontario, Canada: evidence from health administrative data. Gut 2009;58:1490-7.

17. Benchimol El, Guttmann A, Mack DR, et al. Validation of international algorithms to identify adults with inflammatory bowel disease in health administrative data from Ontario, Canada. J Clin Epidemiol 2014;67:887-96.

18. 1996/97 National Population Health Survey: household component, cross-sectional (NPHS). Ottawa: Statistics Canada; 1998. Available: www23.statcan.gc.ca/imdb/ p2SV.pl?Function=getSurvey\&ld=4520 (accessed 2018 Aug. 2). 
19. 2000-2001 (Cycle 1.1) Canadian Community Health Survey (CCHS). Ottawa: Statistics Canada; 2002. Available: www23.statcan.gc.ca/imdb/p2SV.pl? Function =getSurvey\&ld=3359 (accessed 2018 Aug. 2).

20. 2009/2010 Canadian Community Health Survey (CCHS). Ottawa: Statistics Canada; 2011. Available: www23.statcan.gc.ca/imdb/p2SV.pl?Function=getSurvey \&Id=81424 (accessed 2018 Aug. 2).

21. Béland Y. Canadian Community Health Survey - methodological overview. Health Rep 2002;13:9-14.

22. Canadian Community Health Survey (CCHS) - annual component. User guide 2010 and 2009-2010 microdata files. Ottawa: Statistics Canada; 2011. Available: www. statcan.gc.ca/eng/statistical-programs/document/3226_D7_T9_V8 (accessed 2018 Aug. 2).

23. Furlong WJ, Feeny DH, Torrance GW, et al. The Health Utilities Index (HUI) system for assessing health-related quality of life in clinical studies. Ann Med 2001;33:375-84.

24. Feeny D, Furlong W, Torrance GW, et al. Multiattribute and single-attribute utility functions for the health utilities index mark 3 system. Med Care 2002;40: 113-28.

25. Glazier RH, Creatore MI, Agha MM, et al. Socioeconomic misclassification in Ontario's health care registry. Can J Public Health 2003;94:140-3.

26. Chiang CL. The life table and its applications. Malabar (FL): Robert E. Krieger Publishing Company; 1984.

27. Hsieh JJ. A general theory of life table construction and a precise abridged life table method. Biom J 1991;33:143-62.

28. Zou G. A modified Poisson regression approach to prospective studies with binary data. Am J Epidemiol 2004;159:702-6.

29. Woodruff RS. A simple method for approximating the variance of a complicated estimate. J Am Stat Assoc 1971;66:411-4.

30. Sullivan DF. A single index of mortality and morbidity. HSMHA Health Rep 1971;86:347-54.

31. Greenley RN, Kunz JH, Schurman JV, et al. Abdominal pain and health related quality of life in pediatric inflammatory bowel disease. J Pediatr Psychol 2012;38:63-71.

32. Wojtowicz AA, Greenley RN, Gumidyala AP, et al. Pain severity and pain catastrophizing predict functional disability in youth with inflammatory bowel disease. J Crohns Colitis 2014;8:1118-24.
33. Zeitz J, Ak M, Müller-Mottet $\mathrm{S}$, et al. Pain in IBD patients: very frequent and frequently insufficiently taken into account. PLoS One 2016;11:e0156666-13.

34. Neuendorf R, Harding A, Stello N, et al. Depression and anxiety in patients with inflammatory bowel disease: a systematic review. J Pyschosom Res 2016;87: 70-80.

35. Graff LA, Walker JR, Bernstein CN. Depression and anxiety in inflammatory bowel disease: a review of comorbidity and management. Inflamm Bowel Dis 2009;15:1105-18.

36. Conley S, Proctor DD, Jeon S, et al. Symptom clusters in adults with inflammatory bowel disease. Res Nurs Health 2017;40:424-34.

37. Severs M, Spekhorst LM, Mangen M-JJ, et al. Sex-related differences in patients with inflammatory bowel disease: results of 2 prospective cohort studies. Inflamm Bowel Dis 2018;24:1298-306.

38. Ditisheim S, Fournier N, Juillerat $\mathrm{P}$, et al. Inflammatory articular disease in patients with inflammatory bowel disease. Inflamm Bowel Dis 2015;21: 2598-604.

39. Perera LP, Radigan M, Guilday C, et al. Presence of irritable bowel syndrome symptoms in quiescent inflammatory bowel disease is associated with high rate of anxiety and depression. Dig Dis Sci 2019;64:1923-8.

40. Abdalla MI, Sandler RS, Kappelman MD, et al. Prevalence and impact of inflammatory bowel disease-irritable bowel syndrome on patient-reported outcomes in CCFA partners. Inflamm Bowel Dis 2017;23:325-31.

41. Perron L, Simard M, Brisson J, et al. Standard period life table used to compute the life expectancy of diseased subpopulations: more confusing than helpful. Am J Public Health 2017;107:1615-20.

42. Keyfitz N. Introduction to the mathematics of population. London (UK): AddisonWesley; 1968.

43. Benchimol El, Smeeth L, Guttmann A, et al. The REporting of studies Conducted using Observational Routinely-collected health Data (RECORD) statement. PLoS Med 2015;12:e1001885.

44. Olén O, Askling J, Sachs MC, et al. Childhood onset inflammatory bowel disease and risk of cancer: a Swedish nationwide cohort study 1964-2014. BMJ 2017;358:j3951.

45. Hindryckx $P$, Novak G, Bonovas $S$, et al. Infection risk with biologic therapy in patients with inflammatory bowel disease. Clin Pharmacol Ther 2017;102: 633-41.

\section{Competing interests: None declared.}

This article has been peer reviewed.

Affiliations: Division of Gastroenterology, Hepatology and Nutrition (Benchimol), The Hospital for Sick Children, Toronto, Ont.; Children's Hospital of Eastern Ontario (CHEO) Inflammatory Bowel Disease Centre, Division of Gastroenterology, Hepatology and Nutrition (Kuenzig, Benchimol: during the conduct of the study), CHEO and CHEO Research Institute; ICES uOttawa (Kuenzig, Manuel, Donelle, Benchimol); Ottawa Hospital Research Institute (Manuel, Donelle); School of Epidemiology and Public Health (Manuel, Benchimol), University of Ottawa; Department of Pediatrics (Benchimol), University of Ottawa, Ottawa, Ont.

Contributors: M. Ellen Kuenzig, Douglas Manuel and Eric Benchimol conceived the study concept and design. M. Ellen Kuenzig and Jessy Donelle performed the statistical analysis and $\mathrm{M}$. Ellen Kuenzig drafted the manuscript. All of the authors acquired and interpreted the data, critically revised the manuscript for important intellectual content, gave final approval for the version to be published and agreed to be accountable for all aspects of the work.

Funding: M. Ellen Kuenzig was supported by a Post-Doctoral Fellowship Award from the Canadian Institutes of Health Research (CIHR), Canadian Association of Gastroenterology (CAG), and Crohn's and Colitis Canada. Eric Benchimol was supported by a New Investigator Award from the CIHR, CAG and Crohn's and Colitis Canada. Eric Benchimol was also supported by the Career Enhancement Program of the Canadian Child Health Clinician Scientist Program.

Disclaimer: This study was supported by ICES, which is funded by an annual grant from the Ontario Ministry of Health and Long-Term Care (MOHLTC). The opinions, results and conclusions reported in this paper are those of the authors and are independent from the funding sources. No endorsement by ICES or the Ontario MOHLTC is intended or should be inferred. Parts of this material are based on data and/or information compiled and provided by the Canadian Institute for Health Information (CIHI). However, the analyses, conclusions, opinions and statements expressed in the material are those of the author(s), and not necessarily those of $\mathrm{ClHI}$. No external grant support was provided for this study.

Data sharing: The data from this study is held securely in coded form at ICES. While data sharing agreements prohibit ICES from making the data set publicly available, access may be granted to those who meet prespecified criteria for confidential access (available at www.ices.on.ca/DAS). The full data set creation plan and underlying analytic code are available from the authors upon request, with the understanding that the programs may rely upon coding templates or macros that are unique to ICES.

Accepted: June 23, 2020

Correspondence to: Eric Benchimol, eric.benchimol@sickkids.ca 